\title{
Sporulation in Bacillus subtilis 168. Control of Synthesis of Alkaline Phosphatase
}

\author{
By W. D. GRANT \\ Microbiology Unit, Department of Biochemistry, University of Oxford, $O X_{\mathrm{I}} 3 Q U^{*}$
}

(Received 19 December 1973)

SUMMAR Y

Seven mutants which have low activities of vegetative (phosphate-repressible) alkaline phosphatase have been mapped by transduction crosses. These mutations do not affect the production of the alkaline phosphatase associated with sporulation. All the evidence available suggests that the activities produced in phosphatestarvation and during sporulation are attributable to the same protein and derive, presumably, from a common structural gene. It thus appears that alkaline phosphatase has distinct sporulation and vegetative controls and that all the mutations so far examined have been of the regulator type. The position on the chromosome of the structural gene is still in doubt.

\section{INTRODUCTION}

Although the synthesis of alkaline phosphatase by Bacillus subtilis is repressed when the organism is grown in the presence of inorganic phosphate (Anagnostopoulos, 1960) sporulating cultures of $B$. subtilis 168 produce an alkaline phosphatase which is apparently insensitive to such repression (Warren, 1968). A comparative study of the properties of the 'vegetative' and 'sporulation' alkaline phosphatases led Glenn \& Mandelstam (I97I) to conclude that they are probably the same protein species. These authors suggested that a common structural gene for the enzyme may be regulated by two distinct control mechanisms, one of which is associated with phosphate starvation while the other is specific to the sporulation process.

In support of this suggestion, Glenn (197I) isolated a number of mutants of Bacillus subtilis 168 which were defective in the synthesis of 'vegetative' alkaline phosphatase but were capable of producing the enzyme during sporulation. These mutants, however, sporulated only poorly, and produced variable activities of the 'sporulation' phosphatase.

The present work describes the genetic transfer of the defective 'vegetative' phosphatase character from these and other, similar, mutants into strains isogenic with the wild-type organism. Whereas the strains constructed in this way retained the 'vegetative' phosphatasenegative phenotype of the original isolates, each of them was able to sporulate normally and to synthesize 'sporulation' phosphatase activity equal to that of the wild type. The isolation of these strains provides evidence that synthesis of alkaline phosphatase in Bacillus subtilis is under the control of two regulatory systems, one associated with inorganic phosphate starvation of vegetative cells and the other with the participation of this enzyme in the development of the endospore.

\footnotetext{
* Present address: Cawthron Institute, Nelson, New Zealand.
} 
Table I. Strains of Bacillus subtilis used in transduction and transformation experiments

\begin{tabular}{|c|c|c|}
\hline Strain no. & Genotype & Source \\
\hline BD4O & $\arg A_{3}$ phe-I2 & D. Dubnau \\
\hline GSY289 & $u r a-I \operatorname{trp} C 2$ & C. Anagnostopoulos \\
\hline GSY 334 & leu-8 & C. Anagnostopoulos \\
\hline GSY $860^{\circ}$ & $\arg A t I$ nic- 38 & C. Anagnostopoulos \\
\hline MB3 & phe-12 & P. J. Piggot \\
\hline MB2O & leu-8 $\operatorname{trp} C 2$ rif $^{\mathrm{r}}$ tal $^{\mathrm{r} *}$ & P. J. Piggot \\
\hline MB2 I & $\mathrm{met}_{3}$ leu-8 $\mathrm{tal}^{\mathrm{r}}$ & P. J. Piggot \\
\hline MB26 & leu-8 phe-I2 rif $^{\mathrm{r}}$ tal $^{\mathrm{r}}$ & $\begin{array}{l}\text { phe- } 12 \text { transformed into MB } 20 \text { by } \\
\text { congression with } t r p^{+}\end{array}$ \\
\hline
\end{tabular}

\section{METHODS}

Organisms. The organism referred to as the 'wild type' in this communication is Bacillus subtilis Marburg I68 (trp C2), which sporulates normally when supplied with tryptophan or indole. The auxotrophic strains used for transduction and transformation experiments are listed in Table I. The following 'phosphatase-negative' ( $p h o$ ) mutants were studied: NP4. I, NP2I I, NP22. I and NP23. I, which were isolated after mutagenesis of the wild type as described below; $P_{11}, R_{2} R_{1}$ and $R_{7} R_{1}$, also derived from $B$. subtilis $\mathrm{I} 68$, which were isolated by $\mathrm{Dr} A$. R. Glenn in this laboratory; Al-I, VI 2 and V43, which were derivatives of B. subtilis I60 and were gifts from Dr T. Miki (Miki, Minami \& Ikeda, 1965).

Media. Growth and sporulation media were as described by Coote (1972a). In order to ensure complete derepression of synthesis of 'vegetative' alkaline phosphatase in colonies growing on agar plates, the inorganic phosphate concentration of the glucose-glutamate minimal agar medium was lowered to $0.05 \mathrm{mM}$. This medium is referred to as LP (low phosphate) agar.

Measurement of 'vegetative' alkaline phosphatase activity. Derepression of 'vegetative' alkaline phosphatase synthesis in liquid cultures of Bacillus subtilis strains was achieved essentially as described by Glenn \& Mandelstam (I97I). Their method of assay of the 'vegetative' enzyme was also adopted.

Sporulation and measurement of 'sporulation' alkaline phosphatase activity. Sporulation experiments were performed using the resuspension method of Sterlini \& Mandelstam (1969). The production of alkaline phosphatase by a sporulating culture was monitored as follows. Samples $(\mathrm{I} \cdot 0 \mathrm{ml})$ of the culture were removed at $30 \mathrm{~min}$ intervals and centrifuged. The cells were suspended in $\mathrm{I} \cdot 0 \mathrm{M}$-diethanolamine- $\mathrm{HCl}$ buffer, $\mathrm{pH} 10 \cdot 0(\mathrm{I} \cdot 0 \mathrm{ml})$, one drop of toluene was added, and the suspension shaken vigorously for $60 \mathrm{~s}$. One $\mathrm{ml}$ of $p$-nitrophenyl phosphate solution ( $\mathrm{I} \mathrm{mg} / \mathrm{ml}$ in the diethanolamine- $\mathrm{HCl}$ buffer) was then added and the reaction mixture was incubated at $37^{\circ} \mathrm{C}$ for a known time (10 to $15 \mathrm{~min}$ ). The reaction was stopped by the addition of $2 \mathrm{M}-\mathrm{NaOH}(\mathrm{I} \cdot 0 \mathrm{ml})$ after which the suspension was centrifuged. The extinction of the supernatant solution was measured at $4 \mathrm{IO} \mathrm{nm}$. One unit of alkaline phosphatase activity is defined as the amount which catalyses the hydrolysis of I nmol of $p$-nitrophenyl phosphate/min, and specific activities are expressed as units/mg dry wt of cells.

Isolation of mutants. Mutants were obtained by treatment of the wild type with $N$-methyl$N^{\prime}$-nitro- $N$-nitrosoguanidine (NTG). A culture ( $10 \mathrm{ml}$ ) in exponential phase of growth was centrifuged. The cells were suspended in glutamate minimal medium ( $10 \mathrm{ml}$ ) which con- 
tained NTG at a final concentration of $\mathrm{I} 25 \mu \mathrm{g} / \mathrm{ml}$. After this suspension had been shaken at $37{ }^{\circ} \mathrm{C}$ for $30 \mathrm{~min}$, samples $(0.75 \mathrm{ml})$ were pipetted into $25 \mathrm{ml}$ volumes of glucose-glutamate minimal medium in $250 \mathrm{ml}$ shake flasks. These were shaken overnight at $37^{\circ} \mathrm{C}$, then diluted and plated on LP agar. After incubation at $37^{\circ} \mathrm{C}$ for 2 days, the plates were sprayed at room temperature with a solution of $p$-nitrophenyl phosphate $(15 \mathrm{mg} / \mathrm{ml}$ in $\mathrm{I} \cdot 0 \mathrm{M}$-diethanolamine$\mathrm{HCl}$ buffer, $\mathrm{pH}$ I0.0). Colonies with low alkaline phosphatase activity remained white, while normal colonies immediately turned a bright yellow. The white colonies were picked, streaked on glucose-glutamate minimal agar, then restreaked on LP agar to confirm their 'phosphatase-negative' ( $p h o$ ) character.

Mapping of pho mutants. Transducing lysates of phosphatase mutants were prepared from subcultures of the original isolates using phage PBS-I as described by Karamata \& Gross (1970) and adapted by Coote $(1972 b)$. The lysates were used to transduce auxotrophic strains, essentially as described by Coote $(1972 b)$. Transduced cultures and controls were plated on LP agar which lacked the appropriate auxotrophic requirement of the recipient strain. After incubation for 2 days at $37^{\circ} \mathrm{C}$ the colonies transduced to prototrophy were screened for their 'vegetative' alkaline phosphatase character by spraying the plates with a solution of $p$-nitrophenyl phosphate as described above. A clearer and longer-lasting distinction between the pho and $p h o^{+}$colonies was obtained if the plates were chilled to $4{ }^{\circ} \mathrm{C}$ before they were sprayed. The validity of this method of scoring pho and pho+ inheritance was confirmed by retesting a number of the transductant clones of each type after they had been picked and restreaked to single colonies.

In the three-factor crosses, MB26 (leu-8 pho+ phe-12) was transduced with the lysates of the phosphatase mutants $\left(l e u^{+}\right.$pho $\left.p h e^{+}\right)$. leu transductants were selected and transferred to LP plates with and without phenylalanine supplement. The inheritance of the phe character was then determined by inspection, and that of the pho character by spraying the phenylalanine-supplemented plates with $p$-nitrophenyl phosphate solution as described above.

Preparation of 'isogenic' strains. Strain MB2 I (metC3 leu-8 tal ), isogenic with the wild type except in its known genetic markers, was transformed with DNA from alkaline phosphatase mutants by the method of Ephrati-Elizur (1968) as used by Piggot (1973). $\mathrm{leu}^{+}$transformants were selected. The need for a counter-selection against growth of donor bacteria in this transformation procedure was satisfied by the auxotrophic requirements of the phosphatase mutants (tryptophan or arginine). A small number of the $l e u^{+}$transformants inherited the pho character by congression.

\section{RESULTS}

'Phosphatase-negative' (pho) mutants. When grown on LP agar, all ten 'phosphatasenegative' mutants used in the present study were apparently devoid of alkaline phosphatase activity, but experiments with liquid cultures showed that, upon removal of inorganic phosphate from the medium, some alkaline phosphatase activity could be detected. The maximum activity produced was usually about $\mathrm{I}$ to $3 \%$ of that of a wild-type control culture, and although this varied from one experiment to another with any given mutant, activities greater than $5 \%$ of that produced by the control culture were never recorded.

Genetic mapping of the pho mutants. The seven pho mutants derived from Bacillus subtilis I68 were mapped by two- and three-factor transduction crosses. The results in Table 2 show that all 7 mutations were linked by transduction to $\arg A I I, l e u-8$ and phe-I2, but not to $u r a-I$. As leu is only weakly linked to $\arg A$ (approximately $20 \%$ cotransduction; Dubnau 
Table 2. Two-factor transduction crosses to determine linkage of pho mutations to the markers ura-I, argAII, leu-8 and phe-I2

Linkage to selected markers*

\begin{tabular}{|c|c|c|c|c|}
\hline Mutant & ura-I & $\arg A I I$ & leu-8 & phe- 12 \\
\hline NP4.I & $o(0 / 364)$ & $75(66 / 88)$ & $41(79 / 195)$ & $2 I(154 / 74 I)$ \\
\hline NP2 I I & $0(0 / 210)$ & n.t. & $44(136 / 312)$ & 22 ( $127 / 579)$ \\
\hline NP22. I & $o(0 / 269)$ & 56 (I06/I9I) & $27(34 \mathrm{I} / \mathrm{I} 250)$ & $17(150 / 883)$ \\
\hline NP23 $\cdot$ I & $o(0 / 260)$ & $46(33 / 72)$ & $40(129 / 319)$ & $22(74 / 342)$ \\
\hline$P_{11}$ & $0(0 / 156)$ & $54(368 / 685)$ & $47(46 / 98)$ & 2 I $(159 / 743)$ \\
\hline $\mathbf{R}_{\mathbf{2}} \mathbf{R}_{\mathbf{1}}$ & $0(0 / 308)$ & $60(357 / 599)$ & $51(213 / 420)$ & $23(201 / 879)$ \\
\hline$R_{7} R_{1}$ & $0(0 / 200)$ & $67(139 / 209)$ & $46(188 / 405)$ & $21(179 / 838)$ \\
\hline
\end{tabular}

* PBS-I lysates were prepared on the pho mutants ( $\mathrm{ura}^{+}, \mathrm{arg}^{+}, \mathrm{leu}^{+}$and $\mathrm{phe}^{+}$), and used to transduce GSY289 to ura $^{+}$, GSY860 to $\mathrm{arg}^{+}$, GSY334 to $\mathrm{leu}^{+}$, and MB3 to phe $\mathrm{f}^{+}$. Linkage is shown as percentage cotransduction with the number of transductants in parentheses $\left(p h o /\left(p h o^{+}+p h o\right)\right)$. n.t. $=$ Not tested.

Table 3. Three-factor transduction crosses to determine the position of pho mutations with respect to the leu-8 and phe-I2 markers. Recipient genotype (MB26): leu-8 pho phe-I2 (ooo). Donor genotype: leu $u^{+}$pho phe $e^{+}$(III)

\begin{tabular}{|c|c|c|c|c|c|c|c|c|c|c|}
\hline \multicolumn{4}{|c|}{ Donor } & \multicolumn{4}{|c|}{$\begin{array}{l}\text { Number of transductants } \\
\text { in the recombinant classes }\end{array}$} & \multirow{3}{*}{$\begin{array}{l}\text { Possible } \\
\text { order } \\
\text { leu-pho-phe } \\
\text { leu-phe-pho } \\
\text { pho-leu-phe }\end{array}$} & \multirow{2}{*}{$\begin{array}{l}\text { No. of trans- } \\
\text { ductants in } \\
\text { class requiring } \\
4 \text { cross-overs }\end{array}$} & \multirow[b]{2}{*}{$\begin{array}{l}\text { Suggested } \\
\text { order }\end{array}$} \\
\hline $\begin{array}{l}\text { Selec } \\
\text { marl }\end{array}$ & & $\begin{array}{r}\text { Unselec } \\
\text { marke }\end{array}$ & & 100 & IOI & 110 & I I I & & & \\
\hline$l e u^{+}$ & & o NP4. I & $p h e^{+}$ & 7 & 53 & 22 & 28 & & $\begin{array}{l}53 \\
22 \\
\ldots *\end{array}$ & pho-leu-phe \\
\hline$l e u^{+}$ & & O NP2 I . I & $p h e^{+}$ & 18 & 60 & 7 & 25 & $\begin{array}{l}\text { leu-pho-phe } \\
\text { leu-phe-pho } \\
\text { pho-leu-phe }\end{array}$ & $\begin{array}{r}60 \\
7 \\
-*\end{array}$ & pho- $\left\{\begin{array}{l}\text { leu } \\
\text { phe }\end{array}\right\}$ \\
\hline$l e u^{+}$ & & NP22, I & $p h e^{+}$ & $3 I$ & 59 & 9 & 9 & $\begin{array}{l}\text { leu-pho-phe } \\
\text { leu-phe-pho } \\
\text { pho-leu-phe }\end{array}$ & $\begin{array}{r}59 \\
9 \\
-*\end{array}$ & pho- $\left\{\begin{array}{l}\text { leu } \\
\text { phe }\end{array}\right\}$ \\
\hline $\operatorname{leu}^{+}$ & & NP23·I & $p h e^{+}$ & $2 I$ & 48 & 20 & 19 & $\begin{array}{l}\text { leu-pho-phe } \\
\text { leu-phe-pho } \\
\text { pho-leu-phe }\end{array}$ & $\begin{array}{l}48 \\
20 \\
-*\end{array}$ & pho-leu-phe \\
\hline$l e u^{+}$ & & $\mathbf{P}_{11}$ & $p h e^{+}$ & 13 & 61 & 14 & 24 & $\begin{array}{l}\text { leu-pho-phe } \\
\text { leu-phe-pho } \\
\text { pho-leu-phe }\end{array}$ & $\begin{array}{l}6 I \\
I 4 \\
-*\end{array}$ & pho-leu-phe \\
\hline$l e u^{+}$ & & $\mathbf{R}_{2} \mathbf{R}_{\mathbf{1}}$ & $p h e^{+}$ & 15 & 65 & 17 & 15 & $\begin{array}{l}\text { leu-pho-phe } \\
\text { leu-phe-pho } \\
\text { pho-leu-phe }\end{array}$ & $\begin{array}{l}65 \\
17 \\
-*\end{array}$ & pho-leu-phe \\
\hline$l e u^{+}$ & & $\rho \mathbf{R}_{\mathbf{7}} \mathbf{R}_{\mathbf{1}}$ & $p h e^{+}$ & 17 & 66 & 13 & 15 & $\begin{array}{l}\text { leu-pho-phe } \\
\text { leu-phe-pho } \\
\text { pho-leu-phe }\end{array}$ & $\begin{array}{l}66 \\
13 \\
-*\end{array}$ & pho-leu-phe \\
\hline
\end{tabular}

* Multiple cross-overs are undetectable from the possible order pho-leu-phe.

et al. 1967), the percentage cotransduction figures suggest the order $\arg A-p h o-l e u-p h e$, and this is confirmed by the results of the three-factor crosses (Table 3 ).

Linkage to leu-8 of the pho mutations carried by the 160 -derived strains VI 2 and V43 was also established, although poor transducing activity of lysates prepared from these strains precluded a meaningful estimation of the linkage distance. Linkage of VI 2 and v43 to the $\arg A$ marker can be deduced from the results of Nukushina \& Ikeda (1969) with sp-25, another pho mutant linked by transformation to both VI2 and V43 (Miki et al. 1965). 


\section{Table 4. Sporulation of isogenic strains carrying pho mutations}

Bacteria from an exponential culture in hydrolysed casein medium were centrifuged and resuspended in a simple defined medium to induce sporulation (Sterlini \& Mandelstam, 1969). Samples were taken at intervals for estimation of phosphatase activity which was usually at a maximum after $4 \mathrm{~h}$.

\begin{tabular}{|c|c|c|c|c|}
\hline \multirow[b]{2}{*}{ Mutant* } & \multicolumn{2}{|c|}{ 'Sporulation' phosphatase $\dagger$} & \multicolumn{2}{|c|}{ Refractility $\ddagger$} \\
\hline & I68 (control) & pho strain & I 68 (control) & pho strain \\
\hline NP4.I & $44^{\circ} 0$ & $45^{\circ} 0$ & 70 & 65 \\
\hline NP22 . I & - & $50 \cdot 0$ & 一 & 95 \\
\hline $\mathbf{P}_{11}$ & $33 \cdot 6$ & $32 \cdot 5$ & 74 & 78 \\
\hline $\mathbf{R}_{\mathbf{2}} \mathbf{R}_{\mathbf{I}}$ & $5 I \cdot 6$ & $43 \cdot 5$ & 80 & 70 \\
\hline $\mathbf{R}_{\mathbf{7}} \mathbf{R}_{\mathbf{1}}$ & $42 \cdot 9$ & $38 \cdot 4$ & 80 & 80 \\
\hline Al-I & $37 \cdot 5$ & $29 \cdot 2$ & 65 & 60 \\
\hline VI2 & $31 \cdot 8$ & $25^{\cdot 6}$ & 65 & 65 \\
\hline v43 & $41 \cdot 0$ & $40 \cdot 4$ & 75 & 67 \\
\hline
\end{tabular}

* Original isolate used to construct isogenic strain.

$\uparrow$ Maximum activity (units/mg dry wt of cells) of alkaline phosphatase during sporulation.

$\ddagger$ Percentage of cells containing refractile spores after $7 \mathrm{~h}$ in resuspension medium.

These findings are in accord with the work of Le Hegarat \& Anagnostopoulos (1969) who mapped four alkaline phosphatase mutants by transduction and transformation; these mutants were similar in properties to those used in the present study (C. Anagnostopoulos, personal communication), and were located in a single gene between the $\arg A$ and $\operatorname{leu}$ markers.

Sporulation of the pho mutants. The mutations from eight of the ten pho mutants were transferred by transformation crosses to recipient strains which were isogenic with the wild type except for known genetic markers. Each of the constructed pho strains was then tested for its ability to sporulate in a resuspension culture. Wild type was included as a control in each experiment, and the alkaline phosphatase activities in both cultures were assayed. The results of these experiments are presented in Table 4 . After $7 \mathrm{~h}$ in the resuspension medium the culture of each pho strain was subcultured and subsequently tested for its ability to produce the 'vegetative' alkaline phosphatase. In all cases the 'vegetative' pho phenotype was retained.

These results clearly show that the pho mutations carried by these strains have no effect on sporulation or on the production of 'sporulation' alkaline phosphatase. This conclusion is supported by results of similar experiments on the original isolates of the two remaining mutants, NP2I . I and NP23.r. Both mutants sporulated as well as the wild type, and synthesized normal, wild-type alkaline phosphatase activities during sporulation.

It should be mentioned that, apart from NP2I I I and NP23. I, the original isolates of these pho mutants sporulated only very poorly in resuspension experiments; the yield of refractile spores was never greater than $10 \%$, and the production of 'sporulation' alkaline phosphatase was low and variable. It is likely that this behaviour was the result of multiple mutation, particularly in the case of the mutants induced by NTG mutagenesis (Guerola, Ingraham \& Cerdá-Olmedo, 197I). This emphasizes the importance of using isogenic strains.

\section{DISCUSSION}

Seven mutants have been isolated from Bacillus subtilis 168 which produce very low activities of alkaline phosphatase under normal conditions for derepression of synthesis of the enzyme during vegetative growth. These mutants have been mapped by transduction, 
and the linkage data indicate that all seven mutations lie in a region between the $\arg A$ and leu markers on the chromosome. It has been demonstrated that strains carrying these mutations sporulate normally and produce the same level of 'sporulation' alkaline phosphatase as does the wild-type control. If, as seems likely from the work of Glenn \& Mandelstam (1971), the 'vegetative' and 'sporulation'alkaline phosphatases are coded by a common structural gene, the present results imply that the mutations mapped in the arg $A-l e u$ region are in a regulatory gene (or genes) specifically concerned with control of synthesis of the 'vegetative' enzyme. Control of synthesis of the 'sporulation' phosphatase is thus an independent, or at least partly independent, process with its own control genes.

In their genetic studies on ten pho mutants derived from Bacillus subtilis 160 , Miki et al. (1965) found that, although all ten mutations were linked by transformation, they could be divided into two clusters, P-I and P-II. Indirect evidence suggested that P-I represented the structural gene and P-II a regulatory gene for alkaline phosphatase synthesis, and this interpretation has been adopted in recent reviews of the genetics of B. subtilis (Dubnau, 1970; Young \& Wilson, 1972). As has been described above, three of the mutants used by Miki et al. (1965) have been studied in the present work, viz Al-I and V43 from the P-I region, and VI 2 from the P-II region. Our results show that the pho mutations in these three strains have no effect on the production of normal alkaline phosphatase activity during sporulation. In view of the findings of Glenn \& Mandelstam (197I), this implies that these mutations too are in a regulatory gene (or genes) rather than a structural gene. It is concluded that there are at least two 'vegetative' regulation sites as well as a 'sporulation' regulation site and that the position of the structural gene for alkaline phosphatase on the chromosome of $\boldsymbol{B}$. subtilis is still undetermined.

I thank Mrs Sonia Higgs and Mrs Jennifer Higdon for excellent technical assistance. I am indebted to Dr P. J. Piggot for valuable advice on genetic techniques and to Professor J. Mandelstam for many helpful discussions. This work was carried out during the tenure of a Guinness Fellowship.

\section{REFERENCES}

ANAGNostopoulos, C. (1960). Alkaline phosphatase formation in Bacillus subtilis. Federation Proceedings I9, 48.

CoOTE, J. G. (1972a). Sporulation in Bacillus subtilis. Characterization of oligosporogenous mutants and comparison of their phenotypes with those of asporogenous mutants. Journal of General Microbiology 7I, I-I5.

CoOTE, J. G. (1972 b). Sporulation in Bacillus subtilis. Genetic analysis of oligosporogenous mutants. Journal of General Microbiology 7r, 17-27.

DuBNaU, D. (1970). Linkage map of Bacillus subtilis. In Handbook of Biochemistry, 2nd edn, pp. I-39-I-45. Edited by H. A. Sober. Cleveland, Ohio: Chemical Rubber Company.

Dubnau, D., Goldthwaite, C., Smith, G. \& Marmur, J. (1967). Genetic mapping in Bacillus subtilis. Journal of Molecular Biology 27, 163-185.

EPhrati-ElizUR, E. (1968). Spontaneous transformation in Bacillus subtilis. Genetical Research II, 83-96.

GlenN, A. R. (I97I). Sporulation in Bacillus subtilis. D.Phil. thesis, University of Oxford.

GLenN, A. R. \& MANDELSTAM, J. (I97I). Sporulation in Bacillus subtilis I68. Comparison of alkaline phosphatase from sporulating and vegetative cells. Biochemical Journal 123, I29-138.

Guerola, N., Ingraham, J. L. \& Cerdí-Olmedo, E. (I97I). Induction of closely linked multiple mutations by nitrosoguanidine. Nature New Biology 230, I22-1 25.

Karamata, D. \& Gross, J. D. (1970). Isolation and genetic analysis of temperature-sensitive mutants of B. subtilis in DNA synthesis. Molecular and General Genetics 108, 277-287.

Le Hegarat, J.-C. \& ANAGnostopoulos, C. (I969). Localisation chromosomique d'un gène gouvernant la synthèse d'une phosphatase alcaline chez Bacillus subtilis. Comptes rendus hebdomadaire des séances de l'Academie des sciences D 269, 2048-2050. 
Miki, T., Minami, Z. \& IKedA, Y. (1965). The genetics of alkaline phosphatase formation in Bacillus subtilis. Genetics 52, 1093-I100.

NUKUSHINA, J. I. \& IKEDA, Y. (1969). Genetic analysis of the developmental processes during germination and outgrowth of Bacillus subtilis spores with temperature-sensitive mutants. Genetics 63, 63-74.

PIGGoT, P. J. (1973). Mapping of asporogenous mutations of Bacillus subtilis: a minimum estimate of the number of sporulation operons. Journal of Bacteriology 114, 124I-1253.

STERLinI, J. M. \& MANDELSTAM, J. (I969). Commitment to sporulation in Bacillus subtilis and its relationship to development of actinomycin resistance. Biochemical Journal 113, 29-37.

WARREN, S. C. (1968). Sporulation in Bacillus subtilis. Biochemical changes. Biochemical Journal rog, 8I I818.

Young, F. E. \& WiLson, G. A. (1972). Genetics of Bacillus subtilis and other Gram-positive sporulating bacilli. In Spores, vol. 5, pp. 77-106. Edited by H. O. Halvorson, R. Hanson and L. L. Campbell. Washington, D.C.: American Society for Microbiology. 